\title{
SOME INEQUALITIES FOR HAUSDORFF OPERATORS
}

\section{Guilian GAO AND YONG ZHONG}

Abstract. In this paper, we give the sufficient and necessary conditions for the boundedness of Hausdorff operators on various function spaces. Moreover, we consider Lipschitz estimates for the commutator of Hausdorff operators. We extend some known results.

Mathematics subject classification (2010): 26D10, 26D15, 46E30.

Keywords and phrases: Hausdorff operator, Cesàro operator, commutator, Morrey-Herz space.

\section{REFERENCES}

[1] J. Alvarez, J. Lakey And M. GuZmán-Partida, Spaces of bounded $\lambda$-central mean oscillation, Morrey spaces and $\lambda$-central Carleson measures, Collect. Math. 51 (2000), 1-47.

[2] K.F. ANDERSEN, Boundedness of Hausdorff operators on $L^{p}\left(\mathbb{R}^{n}\right), H^{1}\left(\mathbb{R}^{n}\right)$, and $B M O\left(\mathbb{R}^{n}\right)$, Acta Sci. Math.(Szeged) 69 (2003), 409-418.

[3] G. BROWN AND F. MóRICZ, The Hausdorff operator and the quasi Hausdorff operators on the space $L^{p}, 1 \leqslant p<\infty$, Math. Inequal. Appl. 3 (2000), 105-115.

[4] G. BRown AND F. MóRICZ, Multivariate Hausdorff operators on the spaces $L^{p}\left(\mathbb{R}^{n}\right)$, J. Math. Anal. Appl. 271 (2002), 443-454.

[5] J.C. Chen, D.S. FAN AND J. Li, Hausdorff operators on function spaces, Chin. Ann. Math. Ser. B 33 (2012), 537-556.

[6] J.C. Chen, D.S. FAn AND C.J.ZHANG, Multilinear Hausdorff Operators and Their Best Constants, Acta Math. Sin. Ser. B. 28 (2012), 1521-1530.

[7] J.C. Chen, D.S. FAn And C.J. Zhang, Boundedness of Hausdorff Operators on Some Product Hardy Type Spaces, Appl. Math. J. Chin. Univ. Ser. B. 27 (2012), 114-126.

[8] Z.W. Fu, Hardy operators, singular integrals and related topics, Ph. D. Thesis, Beijing Normal University, 2011.

[9] G.L. GaO And H.Y. JiA, Commutators of high dimensional Hausdorff operators, J. Funct. Spaces Appl. 2012, Art. ID 541205, 12 pp. (doi:10.1155/2012/541205).

[10] D.V. Giang AND F. MóRICZ, The Cesàro operator is bounded on the Hardy space $H^{1}$, Acta Sci. Math. 61 (1995), 535-544.

[11] D.V. Giang AND F. Móricz, The two dimensional Cesàro operator is bounded on the multiparameter Hardy space $H^{1}(\mathbb{R} \times \mathbb{R})$, Acta Sci. Math. 63 (1997), 279-288.

[12] C. Georgakis, The Hausdorff mean of a Fourier-Stieltjes transform, Proc. Amer. Math. Soc. 116 (1992), 465-471.

[13] R.R. Goldberg, Convolutions and general transforms on $L^{p}$, Duke Math. J. 27 (1960), 251-259.

[14] L. Grafakos, Classical and Modern Fourier Analysis, Pearson Education, Inc., New Jersey, 2004.

[15] Y. Guo, Boundedness of some operators on non-homogeneous spaces, Master Degree Dissertation, Beijing Normal University.

[16] G.H. HARDY, Divergent Series, Oxford University Press, 1949.

[17] G.H. HARDY, Notes on some points in the integral calculus, Messenger Math. 58 (1929), 50-52.

[18] Y. KAnJin, The Hausdorff operators on the real Hardy spaces $H^{p}(\mathbb{R})$, Studia Math. 148 (2001), $37-45$.

[19] A. LeRner And E. Liflyand, Multidimensional Hausdorff operators on the real Hardy spaces, J. Austr. Math. Soc. 83 (2007), 79-86.

[20] E. Liflyand, Boundedness of multidimensional Hausdorff operators on $H^{1}\left(\mathbb{R}^{n}\right)$, Acta Sci. Math.(Szeged) 74 (2008), 845-851. 
[21] E. Liflyand, Complex and real Hausdorff operators, http://www.crm.es/Publications/11/ Pr1046.pdf.

[22] E. LIFLYAND AND F. MóRICZ, The Hausdorff operators is bounded on the real Hardy space $H^{1}(\mathbb{R})$, Proc. Amer. Math. Soc. 128 (2000), 1391-1396.

[23] E. LifLYAND AND F. MóRICZ, The multi-parameter Hausdorff operator is bounded on the product Hardy space $H^{11}(\mathbb{R} \times \mathbb{R})$, Analysis 21 (2001), 107-118.

[24] E. LifLYAND AND A. MiYACHI, Boundedness of the Hausdorff operators in $H^{p}$ spaces, $0<p<1$, Studia Math. 194 (2009), 279-292.

[25] S.Z. LU AND L.F. XU, Boundedness of rough singular integral operators on the homogeneous Morrey-Herz spaces, Hokkai. Math. J. 34 (2005), 299-313.

[26] S.Z. Lu, D.C. Yang, And G.E. Hu, Herz Type Spaces and Their Application, pp. Science PressBeijing, China, 2008.

[27] A. MiYACHI, Boundedness of the Cesàro operator in Hardy spaces, J. Fourier Anal. Appl. 10 (2004), 83-92.

[28] F. MóRICZ, Multivariate Hausdorff operators on the spaces $H^{1}\left(\mathbb{R}^{n}\right)$ and $B M O\left(\mathbb{R}^{n}\right)$, Anal. Math. 31 (2005), 31-41.

[29] M. PAluszynski, Characterization of Bosev spaces via the commutator operator of Coifman, Rochberg and Weiss, Indi. Univ. Math. J. 44 (1995), 1-18.

[30] A.G. Siskakis, The Cesàro operator is bounded on $H^{1}$, Proc. Amer. Math. Soc. 110 (1990), 461462.

[31] C.Q. TAng And Z.C. ZhaI, Generalized Poincaré embeddings and weighted Hardy operator on $Q_{p}^{\alpha, q}$ spaces, J. Math. Anal. Appl. 371 (2010), 665-676.

[32] F. WEISZ, The boundedness of the Hausdorff operator on multi-dimensional Hardy spaces, Analysis 24 (2004), 183-195.

[33] J. XIAO, $L^{p}$ and BMO bounds of weighted Hardy-Littlewood averages, J. Math. Anal. Appl. 262 (2001), 660-661. 